Marcello Garzaniti (Firenze)

\title{
LE PIÙ RECENTI RICERCHE SUI VANGELI SLAVI (1999-2016) QUALCHE RIFLESSIONE CRITICA
}

\section{Premessa}

$\mathrm{Q}$ uindici anni fa uscì in Germania la monografia Die altslavische Version der Evangelien. Forschungsgeschichte und zeitgenössische Forschung ${ }^{1}$, in cui ho voluto presentare la produzione scientifica sulla versione slava dei vangeli dalle prime ricerche di J. Dobrovský fino alla fine del XX sec. esaminando criticamente i principali risultati.

Quando mi è stato proposto di realizzare una versione in lingua russa del volume, ho creduto necessario aggiornare questa bibliografia e presentare le più recenti ricerche. Nel complesso si deve riconoscere che in questi ultimi quindici anni sono stati raggiunti nuovi e importanti risultati e che questo campo di studi rappresenta ancora un tema fondamentale della slavistica nellambito della paleografia, della critica testuale e dell'analisi linguistica.

La diffusione della tecnologia informatica e la pratica della digitalizzazione rendono ora disponibili non solo gran parte dei materiali bibliografici, comprese le tesi di dottorato, ma persino la riproduzione fotografica dei manoscritti. In tal modo ho potuto coprire diverse lacune nella bibliografia precedente e avere facilmente a disposizione preziosi materiali. A ciò si deve aggiungere la creazione di portali dedicati alla tradizione manoscritta dei vangeli greci o slavi o più in generale alla tradizione manoscritta medievale che contengono anche corpora interrogabili. Tutto questo sta trasformando il modo di lavorare delle nuove generazioni di ricercatori.

\section{La tradizione manoscritta greca}

La versione slava dei vangeli, è opportuno ricordarlo, ha le sue basi nella traduzione di un ignoto originale greco, mentre la successiva tradizione manoscritta slava si è sviluppata, pur con leccezione della tradizione croato-glagolitica, in stretta

\footnotetext{
${ }^{1}$ M. GarZaniti, Die altslavische Version der Evangelien. Forschungsgeschichte und zeitgenössische Forschung, Köln-Weimar-Wien 2001.
} 
connessione con la tradizione greca. Per questo è molto importante seguire con attenzione i progressi nelle ricerche sui vangeli greci.

Questi anni hanno visto nuovi importanti sviluppi nelle ricerche dell'International Greek New Testament Project (IGNTP). Dopo aver offerto negli anni ottanta un significativo contributo allo studio della tradizione manoscritta del Vangelo di Luca $^{2}$, il progetto si è concentrato sul Vangelo di Giovanni. Dopo l'uscita a stampa delledizione secondo la testimonianza dei papiri ${ }^{3}$, il gruppo di studiosi, sotto la guida di D.C. Parker, ha cominciato a collaborare all'Editio Critica Maior del Nuovo testamento, promossa dall'Institut für neutestamentliche Textforschung (INTF, Münster, v. infra), assumendosi la responsabilità di preparare l'edizione del Vangelo di Giovanni (2005) ${ }^{4}$. Dopo aver pubblicato le testimonianze dei codici maiuscoli ${ }^{5}$, è stato creato un portale che offre on line l'edizione dei codici maiuscoli sulla base della seconda edizione a stampa $(2013)^{6}$ e promette la progressiva trascrizione dei papiri, dei codici maiuscoli e minuscoli e, infine, dei lezionari ${ }^{7}$. Allo stesso tempo nell'ambito del medesimo progetto, su richiesta di un gruppo di chiese ortodosse, è stata pubblicata l'edizione del medesimo vangelo secondo la tradizione bizantina, uscita prima in forma cartacea $^{8} \mathrm{e}$ in seguito aggiornata nella forma digitale ${ }^{9}$ che comprende codici maiuscoli e minuscoli, ma anche lezionari e testimonianze dei vangeli commentati.

Nel frattempo l'INTF di Münster, sempre nell'ambito della preparazione all'Editio Critica Maior del Nuovo testamento, ha offerto un contributo che, come vedremo, può essere di grande rilevanza anche per lo studio della versione slava. Seguendo il metodo "locale-genealogico" 10 sono stati identificati, infatti, alcu-

\footnotetext{
${ }^{2}$ The Gospel According to St Luke. Part One. Chapters 1-12, ed. The American and British Committees of the International Greek New Testament Project, Oxford 1984; The Gospel According to St Luke. Part Two. Chapters 13-24, ed. The American and British Committees of the International Greek New Testament Project, Oxford 1987.

${ }^{3}$ The Gospel According to St John. The Papyri, ed. W.J. Elliott, D.C. Parker, Leiden 1995 (= NTTS 20).

${ }^{4}$ Cf. K. Wachtel, D.C. Parker, The Joint IGNTP/INTF Editio Critica Maior of the Gospel of John. It's Goal and their Significance for New Testament Scholarship Proposed Paper for SNTS 2005 (Halle), www.uni-muenster.de/INTF/ECM\%20Halle6.pdf [15 VI 2016].

${ }^{5}$ The Gospel According to St John. The Majuscules, ed. U.B. Schmid, W.J. Elliott, D.C. Parker, Leiden 2007 (= NTTSD 37).

${ }^{6}$ Cf. www.iohannes.com/majuscule/index.html [15 VI 2016].

${ }^{7}$ Cf. www.iohannes.com/IGNTPtranscripts/index.html [15 VI 2016].

${ }^{8}$ The Gospel According to John in the Byzantine Tradition, ed. R.L. Mullen, S. Crisp, D.C. Parker, Stuttgart 2007.

${ }^{9}$ Cf. www.iohannes.com/byzantine/index.html [15 VI 2016].

${ }^{10}$ Le regole del metodo locale-genealogico ("Lokal-genealogisches Method") per distinguere e interpretare le varianti sono esposte brevemente nello studio di K. e B. Aland (B. Aland, K. Aland, The Text of the New Testament. An Introduction to the Critical Editions and the Theory and Practice of Modern Textual Criticism, Grand Rapids-Leiden 1987, p. 275). Per una sua evoluzione con la definizione di "coherence-based genealogical method", soprattutto in relazione alla complessa questione della contaminazione, si veda G. Mink, Problems of a highly Contaminated Tradition: the New Testament.
} 
ni principali "nodi di varianti", che, a prescindere dalla tradizionale distinzione dei codici in gruppi e famiglie, consentono di raggruppare le testimonianze della tradizione manoscritta greca nel suo complesso. In particolare si distinguono le varianti del cosiddetto "testo standard" dalle lezioni del "testo bizantino", chiamato anche koiné. Il testo bizantino non è semplicemente la versione di Luciano, che si sarebbe conservata immutata nei libri ecclesiastici, come spesso si ritiene, ma un testo, che si è formato nel corso di alcuni secoli, a partire dallarea antiochena. Questo testo è definito sulla base del cosiddetto "testo maggioritario (majority text)", cioè il testo costituito dai passi senza varianti e dalle lezioni, testimoniate dalla maggioranza dei manoscritti ${ }^{11}$.

Sulla base di 467 "nodi di varianti", infatti, sono state analizzate le diverse lezioni di numerosi codici (1984 mss. per i sinottici e 1987 mss. per il vangelo di Giovanni) che sono state messe a disposizione in diversi corposi volumi ${ }^{12}$. Purtroppo il numero dei "nodi" non è omogeneo fra i vangeli e sono stati esclusi dall'analisi gli oltre millecinquecento lezionari. Abbiamo, comunque, a disposizione per i vangeli di Matteo, Marco e Luca e per i primi dieci capitoli di Giovanni un importante strumento per lo studio della tradizione manoscritta greca.

Nell'ambito della tradizione manoscritta dei lezionari, a oltre cinquant'anni dagli studi della scuola di Chicago è uscita la ricerca di Ch.R.D. Jordan, The Textual Tradition of the Gospel of John in Greek Gospel Lectionaries from the Middle Byzantine Period ( $8^{\text {th }}-11^{\text {th }}$ Century). Quest'ampia dissertazione illustra le testimonianze manoscritte più antiche del lezionario greco nei loro diversi aspetti sulla base di un ampio corpus ( 126 codici fra l'VIII e l'XI sec.) e analizza in particolare 44 nodi testuali del vangelo di Giovanni ${ }^{13}$.

Stemmata of Variants as a Source of a Genealogy for Witnesses, [in:] Studies in Stemmatology II, ed. P. Van Reenen, A. Den Hollander, M. Van Mulken, Amsterdam-Philadelphia 2004, p. 13-86.

${ }^{11}$ Der Mehrheitstext des NT besteht aus den unvariiert überlieferten Textabschnitten und der Summe aller Mehrheitslesarten. Eine Mehrheitslesart ist die von der Mehrheit aller griechischen Handschriften des Neuen Testaments bezeugte Lesart einer variierten Stelle... Als Byzantinischer Text wird diejenige Textform bezeichnet, der seit dem 9. Jahrhundert in vielen hundert Exemplaren weitgehend identisch reproduzert wurde. Diese Textform ist seither, nicht zulezt durch die Lektionare, in der griechischen Christenheit allgemein verbreitet und als der Text des Neuen Testaments anerkannt... (K. WACHTEL, Der Byzantinische Text der Katholischen Briefe. Eine Untersuchung zur Entstehung der Koine des Neuen Testaments, Berlin 1995, p. 7). ${ }^{12}$ Cf. Text und Textwert der Griechischen Handschriften des Neuen Testaments. IV. Die Synoptischen Evangelien. 1. Das Markusevangelium, ed. K. Aland, B. Aland, K. Wachtel, K. Witte, vol. II, Berlin-New York 1998; Text und Textwert der Griechischen Handschriften des Neuen Testaments. IV. Die Synoptischen Evangelien, 2. Das Matthäusevangelium, ed. K. Aland, B. Aland, K. Wachtel, K. Witte, vol. II, Berlin-New York 1999; Text und Textwert der Griechischen Handschriften des Neuen Testaments. IV. Die Synoptischen Evangelien. 3. Das Lukasevangelium, ed. K. Aland, B. Aland, K. Wachtel, K. Witte, vol. II, Berlin-New York 1999; Text und Textwert der Griechischen Handschriften des Neuen Testaments. V. Das Johannesevangelium, ed. K. Aland, B. Aland, K. Wachtel, K. Witte, vol. II, Berlin-New York 2005.

${ }^{13}$ Ch.R.D. Jordan, The Textual Tradition of the Gospel of John in Greek Gospel Lectionaries from the Middle Byzantine Period ( $8^{\text {th }}-11^{\text {th }}$ Century). A Thesis Submitted to The University of Birmingham 


\section{Sulla struttura del libro dei vangeli}

Riguardo alla tradizione manoscritta sia greca sia slava, in tempi recenti è cresciuta l'attenzione nei confronti della struttura di questo libro, come dimostrano peraltro le descrizioni contenute nei cataloghi (v. infra). In modo sempre più evidente si percepisce la funzione liturgica, non solo del lezionario, ma anche del tetraevangelo. La testimoniano in particolare le rubriche, le glosse a margine e le appendici, ma la si può riconoscere anche nella forma testuale dei vangeli che mostrano una serie di adattamenti prodotti dalla divisione in pericopi o determinati dall'influenza dei passi paralleli ${ }^{14}$.

Una questione rilevante è stata sollevata, ancora alla fine degli anni novanta, da S.Ju. Temčin che ha individuato, oltre alle note tipologie del lezionario, un "aprakos a colonna". Con questa definizione lo studioso intende una breve raccolta di pericopi del vangelo e dellapostolo con le undici letture dei vangeli domenicali per il mattutino, le otto letture per il sabato e la domenica secondo i toni dellottoeco, le letture per ogni giorno della settimana, cui si può aggiungere una selezione delle pericopi per le feste dei santi $i^{15}$. Se, però, consideriamo la questione nel complesso dei libri liturgici della tradizione bizantino-slava si deve riconoscere che in genere proprio al libro dell'ottoeco è associato l'anthologion (in slavo anfologion $\breve{u}$ ) in cui si offrono i testi delle principali feste liturgiche del calendario fisso e mobile con una serie di pericopi dell'apostolo e dei vangeli ${ }^{16}$. In questa prospettiva si dovrebbero allora considerare anche gli eucologi che contengono una serie di letture dei vangeli per le diverse celebrazioni dei sacramenti. Così ha fatto Temčin che coerentemente si è spinto a parlare di "aprakos eucologico" ${ }^{17}$. Pur ritenendo molto utili

for the Degree of Doctor of Philosophy, Birmingham 2009, www.etheses.bham.ac.uk/578/1/Jordan10PhD.pdf [29 VI 2016].

${ }^{14}$ Recentemente ho pubblicato una versione aggiornata della riflessione sulla struttura del lezionario e del tetraevangelo, contenuta nella nostra monografia: M. GARZANITI, The Gospel Book and its Liturgical Function in the Byzantine-Slavic Tradition, [in:] Catalogue of Byzantine Manuscripts in their Liturgical Context, vol. I, Challenges and Perspective, ed. K. Spronk, G. Rouwhorst, S. Royé, Turnhout 2013, p. 35-54.

${ }^{15}$ С.Ю. Темчин, Столпный апракос - еще один неизвестный структурный тип славянского служебного Евангелия (по рукописям XIII-XVI вв), [in:] Библия в духовной жизни, истории и культуре России и православного славянского мира. К 500-летию Геннадевской Библии. Сборник материалов международной конференции. Москва, 21-26 сентября 1999 г., еd. Г. БАРАнковА, Москва 2001, p. 127-159.

${ }^{16}$ Se ne conserva un'interessante testimonianza nel Codex Hankensteinianus (Wien, Cod. slav. 37), un manoscritto galiziano-voliniano risalente al XIII-XIV sec. del quale G. Birkfellner ha studiato approfonditamente le pericopi e le rubriche (G. Birkfellner, Codex Hankenstein. Codex Vindobonensis slavicus 37. Altukrainisches liturgisches Anthologion des 13.-14. Jahrhunderts. Textus manuscriptus linguae ecclesiastico-slavonicae versionis ucrainicae (parvorossicae) saeculi XIII-XIV, vol. II, Neutestamentliche Perikopen, Evangelien und Apostelschriften, Münster 2006).

${ }^{17}$ С.Ю. Темчин, О возможном балканском влиянии на структуру иерковнославянских богослужебных книг ВКЛ и Польского Королевста, SRu 18, 2000, p. 275-280. 
queste osservazioni, ci sembra, però, che in entrambi i casi abbiamo a che fare con tipologie librarie diverse dal libro dei vangeli che vanno studiate in primo luogo all'interno della propria tradizione manoscritta. Non escludiamo, comunque, che si possano analizzare anche in relazione ai libri del lezionario e del tetraevangelo.

Allo studio dei lezionari ha dato un importante impulso J. Ostapczuk, che oltre a numerosi articoli, ha pubblicato due ampie monografie ${ }^{18}$. Nella prima si offrono in particolare le edizioni di molti frammenti di lezionari e l'analisi di alcune pericopi della liturgia pasquale, del mercoledì della quarta settimana dopo Pasqua e della pentecoste monografia, mentre nella seconda si presenta l'analisi delle pericopi del ciclo matteano.

In quest'ultimo volume si offre una versione aggiornata della lista dei codici presente nella nostra monografia ${ }^{19}$ con l'aggiunta in particolare dei dati offerti dai nuovi cataloghi usciti in questi ultimi quindici anni, fra cui ovviamente occupa un posto di rilievo il primo volume del catalogo dei codici del XIV sec., conservati in Russia, nei paesi SNG e nei paesi baltici ${ }^{20}$. Nella lista si introduce, tuttavia, una serie di nuovi dati che possono creare una certa confusione. Non solo si considerano anche gli ottoechi (v. supra), ma ci si basa anche su cataloghi precedenti il secondo dopoguerra, che non sempre sono affidabili sia per la metodologia, sia a causa dei cambiamenti intervenuti (dispersione o riaggregazione delle raccolte, ecc...). Lo studioso, inoltre, nel comporre la lista non tiene più conto del limite temporale della prima metà del XVI sec., che avevamo giustificato sulla base dell'avvento della stampa e dei possibili influssi reciproci fra tradizione manoscritta e a stampa quando si trasformò radicalmente la trasmissione del libro dei vangeli e in genere delle sacre scritture. Si presenta così una lista più abbondante di codici che offre in ogni caso nuovi spunti alla ricerca ${ }^{21}$.

\footnotetext{
${ }^{18} \mathrm{~J}$. Ostapczuk, Cerkiewnosłowiański przekład liturgicznych perykop okresu paschalnego i święta Pięćdziesiątnicy w rękopiśmiennych ewangeliarzach krótkich, Warszawa 2010; IDEM, Sobotnie i niedzielne perykopy liturgiczne z Ewangelii Mateusza w cerkiewnosłowiańskich lekcjonarzach krótkich, Warszawa 2013.

${ }^{19}$ Cf. M. Garzaniti, Die altslavische Version der Evangelien..., Anhang II.

${ }^{20} \mathrm{Cf}$. Сводный каталог славяно-русских рукописных книг, хранящихся в России, странах СНГ и Балтии. XIV век, vol. I (Апокалипсис - Летопис Лаврентьевская), еd. О.А. КнязевскАЯ, Н.А. КоБяк, А.Л. Лифшиц, Н.Б. Тихомиров, А.А. Турилов, Н.Б. ШелАмАновА, Москва 2002. Grazie a questo catalogo, in particolare, abbiamo avuto la conferma che il cosiddetto Evangelium $\mathrm{Bu}$ covinense, un tetraevangelo già conservato a Černivci e descritto da V. Jagić (V. JAGIĆ, Ein Beitrag zur Erforschung der altkirchenslavischen Evangelientexte (Evangelium Bucovinense), Wien 1916, Sitzungsberichte der Kaiserlichen Akademie der Wissenschaften in Wien. Philosophisch-historische Klasse, 180.1. Abhandlung) si deve identificare con il codice RNB F.p.I.122, acquisito dalla Biblioteca Nazionale russa nel 1945 (e; II metà XIV sec.; ff. 86; Сводный каталог..., 245).

${ }^{21}$ J. OstapCZuK, Sobotnie i niedzielne perykopy liturgiczne..., p. 9-60. Nella monografia segue uno studio dedicato alla presenza dei codici dei vangeli in Polonia in uno spettro temporale molto ampio che arriva alle testimonianze manoscritte di epoca contemporanea.
} 


\section{Le pericopi del menologio}

Uno dei settori che ha visto una più marcata evoluzione è stata la ricerca sul menologio dei lezionari e sulle liste delle pericopi del menologio nei tetraevangeli.

In anni a noi più vicini hanno lavorato in questo ambito E. Dogramadžieva, C. Vakareliyska e O.V. Loseva. Su una base assai ampia di codici Dogramadžieva offre i numerosi dati raccolti in quattro preziose diverse tabelle: la prima contiene un repertorio completo delle letture con le indicazioni della data, della festa, del contenuto della pericope e dei testimoni manoscritti ordinati secondo il calendario; la seconda presenta i dati nell'ordine alfabetico delle memorie liturgiche con l'indicazione della data e della pericope e con le eventuali varianti in corsivo; la terza presenta le pericopi dei vangeli ordinate secondo l'evangelista; la quarta confronta le indicazioni delle pericopi dei codici con la testimonianza del primo vangelo a stampa, realizzato dal monaco Makarije (1512)22. L'imponente lavoro nell'ambito dell'uso liturgico dei vangeli non ha paragoni con analoghe ricerche sui vangeli greci e rappresenta un punto di riferimento fondamentale per gli studi non solo sulla tradizione manoscritta dei vangeli, ma più in generale per la conoscenza della storia della liturgia e dell'agiografia bizantino-slava.

Nei medesimi anni C. Vakareliyska ha creato un archivio informatico delle memorie contenute nei menologi di oltre un centinaio di vangeli (X-XV sec.), che può essere di grande aiuto per lo studio della tradizione manoscritta dei vangeli ${ }^{23}$. Nella sua pubblicazione dedicata al Vangelo di Curzon (Brit.Lib. Add.39628) la studiosa americana ha offerto, inoltre, un importante contributo allo studio dei menologi e delle liste dei menologi dei vangeli slavi di area balcanica sulla base del confronto fra il Vangelo di Banica (NBKM 847) e il Vangelo di Curzon nel contesto del suo vasto corpus di codici ${ }^{24}$.

Per l'area slava orientale una nuova tappa nella storia degli studi è rappresentata dalla monografia di Loseva, che raccoglie i risultati di precedenti ricerche condotte sulla base di oltre centocinquanta vangeli e apostoli ${ }^{25}$. Si dovrebbero poi aggiungere numerosi studi che si occupano dei menologi dei singoli codici o di singole memorie, finalizzate allo studio del culto dei santi e in generale alla conoscenza

\footnotetext{
${ }^{22}$ Е. ДоГрАмАДЖиЕвА, Месеиесловните четива в славянските ръкописни евангелия (X-XVII в.), София 2010 (= КМс 19).

${ }^{23}$ C. Vakareliyska, A Typology of Slavic Menology Traditions, [in:] American Contributions to the $X I V^{\text {th }}$ International Congress of Slavists (Ohrid 2008), vol. I, Linguistics, ed. CH.Y. BETHIN, Bloomington 2008, p. 227-244; C. Vakareliyska, D. Birnbaum, A Computerized Database of Medieval Slavic Gospel Menologies, [in:] Слово: Кәм израждане на дигитална библиотека на южнославянски ръкописи. Доклади от международната конферениия 21-26 февруари, 2008, София, България, ed. Х. МиклАС, А. МилтеновА, София 2008, p. 220-226.

${ }^{24}$ C. Vakareliyska, The Curzon Gospel, vol. II, A Linguistic and Textual Introduction, New York 2008, p. 226-285.

${ }^{25}$ О.В. ЛосевА, Русские месяи,есловы XI-XIV веков, Москва 2001.
} 
della storia del cristianesimo ortodosso. Per ricostruire la storia del menologio slavo, tuttavia, si deve considerare il più ampio contesto della tradizione liturgica bizantino-slava, a cominciare dall'influsso della liturgia della Cattedrale di Santa Sofia in Costantinopoli, come testimonia il confronto con i testimoni del libro del typikon e le menee liturgiche. Per una prima introduzione metodologica e unanalisi delle memorie liturgiche della più antica tradizione manoscritta del vangelo e dellapostolo slavo si possono leggere alcuni nostri lavori ${ }^{26}$.

\section{L’ornamentazione del libro dei vangeli}

Nello studio della tradizione manoscritta dei vangeli assume un ruolo sempre più importante l'analisi dellornamentazione dei codici al di là dell'aspetto estetico delle vignette e delle miniature. Lattenzione degli studiosi recentemente si è concentrata, infatti, sullanalisi della funzione dell'ornamentazione in relazione alla struttura del libro considerando principalmente il suo uso liturgico e, in epoca più tarda, la diffusione dell'uso personale.

Sotto quest'aspetto ha assunto un ruolo centrale la ricerca di E. Musakova, che fin dagli anni novanta ha considerato i più antichi lezionari di redazione bulgara, a partire dal menologio studiando la "segmentazione" testuale dei lezionari sabato-domenicali, creata con l'ausilio dellornamentazione, in relazione alluso liturgico. Fra i suoi numerosi studi si può citare un contributo di ampio respiro con riferimenti alle precedenti ricerche, pubblicato in un volume della serie Drevnerusskoe iskusstvo ${ }^{27}$. La sua ricerca è proseguita con un articolo dedicato interamente al Vangelo di Assemani (Bib.Vat. slav.3) in cui si mette in luce la "struttura gerarchica" delle forme ornamentali in funzione della liturgia sia nel sinassario sia nel menologio. In quest'ultimo è evidente una serie di affinità soprattutto con alcuni lezionari greci di tradizione costantinopolitana (X-XI sec. $)^{28}$. La studiosa si è occupata ugualmente di testimonianze manoscritte più tarde, come il Vangelo di Rila (NBKM 31), NBKM 33 e il Vangelo di Ioan Aleksandr (Brit.Lib. Add.39627). Delle miniature di quest'ultimo codice si è occupato recentemente I.V. Talev,

\footnotetext{
${ }^{26}$ M. Garzaniti, Il culto dei santi nella Slavia ortodossa: la testimonianza dei libri del Vangelo e dell'Apostolo. Sviluppi storici e diffusione geografica: l'eredità bizantina e la formazione della prima tradizione manoscritta (X-XI sec.), [in:] Il tempo dei santi tra Oriente e Occidente. Liturgia e agiografia dal tardo antico al Concilio di Trento, ed. A. Benvenuti, M. Garzaniti, Roma 2005, p. 311-341; IDEM, Il culto dei santi nella Slavia ortodossa alla luce dei libri del Vangelo e dell' Apostolo. Prima parte, [in:] Liturgia e agiografia e tra Roma e Costantinopoli, ed. K. Stantchev, S. PARenti, Grottaferrata 2007, p. 89-108.

${ }^{27}$ E. Moussakova, The Illuminated Old-Bulgarian Gospel Lectionaries in the Light of their probable Byzantine Models, [in:] Древнерусское искусство. Искусство рукописной книги. Византия. Древняя Русь, еd. Е.Н. Доврынина, Санкт-Петербург 2004, р. 277-289.

${ }^{28}$ Е. Мусакова, Графическата сегментация на текста в Асеманиевото евангелие, Slo 56-57, 2006-2007, p. 391-404.
} 
che in genere segue l'interpretazione offerta da B. Filov, ma soprattutto critica l'idea di un 'Rinascimento' (o 'Prerinascimento') slavo delle lettere e delle arti'”29.

Nei medesimi anni E.V. Uchanova ha considerato le più antiche testimonianze glagolitiche mettendole in relazione con i centri scrittori dei monasteri che si mostrano assai più conservativi rispetto alla tradizione delle scuole della capitale bizantina. In particolare la studiosa ha osservato l'affinità con le testimonianze manoscritte dei monasteri dell'Italia meridionale ${ }^{30}$. Nelle successive ricerche sono considerate le più antiche testimonianze manoscritte di area slava orientale, a cominciare dal Vangelo di Ostromir (RNB F.p.I.5) che viene messo in relazione con la tradizione manoscritta occidentale. Sviluppando sistematicamente quanto avevano osservato qualche anno prima O.S. Popova a proposito dei volti raffigurati in alcune lettere capitali (v. infra) e E.S. Smirnova riguardo ai simboli degli evangelisti ${ }^{31}$, la studiosa mette in luce, pur nel perdurante dominio dell'arte bizantina, l'influsso della tradizione manoscritta occidentale di epoca ottoniana ${ }^{32}$.

\section{Le nuove edizioni}

Nellambito delle edizioni dei vangeli costituisce un evento di rilevo la pubblicazione del Vangelo di Matteo, curata a Pietroburgo sotto la direzione di A.A. Alekseev $^{33}$. Quest'edizione, come la precedente del Vangelo di Giovanni (1998), non si basa, infatti, sui metodi tradizionali, ma considerando l'alto numero delle testimonianze manoscritte e il complesso problema della contaminazione, adotta un metodo statistico e sulla base dell'analisi di un breve passo presente nei codici a disposizione cerca di individuare il coefficiente di vicinanza dei manoscritti per raggrupparli nelle diverse redazioni identificandone i principali esponenti. Nella prima appendice del volume D.M. Mironova illustra il metodo adottato indicando che l'individuazione dei tipi testuali è stata condotta su 532 codici nel frammento Mt 14, 14-34 in cui sono stati individuati 545 "unità di varianti" ${ }^{34}$. Naturalmente il metodo adottato non è l'unico possibile, come dimostra un precedente studio di Mironova in cui si confronta la metodologia adottata a Pietroburgo con

\footnotetext{
${ }^{29}$ И.В. ТАлев, Български “предренесанс". Митове и реалност, София 2005.

${ }^{30}$ Е.В. УХАновА, К вопросу о происхождении принципов обормления глаголичеслих рукописей X-XI вв, [in:] Древнерусское искусство. Искусство рукописной книги. Византия. Древняя Русь, ed. Е.Н. Доврынина, Санкт-Петербург 2004, р. 221-244.

${ }^{31}$ Е.С. Смирнова, Миниатюры Остромирова Евангелия. Особенности иконограбии, [in:] Образ Византии. Сборник статей в честь О.С. Поповой, еd. А.В. ЗАхаровА, Москва 2008, p. 457-472.

${ }^{32}$ Е.В. УХанова, Западноевропейские источники в древнерусской книжной културе ХІ века и Остромирово Евангелие, [in:] Путем орнамента. Исследования по искусству Византийского мира. Сборник статей, еd. А.Л. САминский, Москва 2013, р. 206-230.

${ }^{33}$ Евангелие от Матфея...

${ }^{34}$ Д.М. Миронова, Классификация рукописей евангелия от Матфея, [in:] Евангелие от Матфея..., p. 163.
} 
il cosiddetto Three Level Method, messo a punto da E. Wattel, evidenziando quanto siano vicini i risultati ottenuti con entrambi ${ }^{35}$.

Nel frattempo la citata edizione del Vangelo di Giovanni ha ricevuto una serie di recensioni, suscitando un dibattito che ha toccato in particolare la questione della precedenza della versione del tetraevangelo rispetto al lezionario. Non vogliamo entrare nel merito della complessa questione, ma ci limitiamo a segnalare che anche per la versione slava si dovrebbe adottare la distinzione fra archetipo e "testo iniziale" (Ausgangstext), già proposta per la versione per l'originale greco $^{36}$ che aiuterebbe a distinguere fra una prima versione, la cui notizia è attestata dalle fonti cirillometodiane, e le testimonianze manoscritte che riflettono già la stratificazione del testo iniziale da collocarsi preferibilmente nell'impero bulgaro della fine del IX sec.

Si deve riconoscere, comunque, che in generale il testo greco con le sue varianti rimane in secondo piano ancora in questa edizione anche se il suo vasto apparato può aiutarci a orientarci nel mare magnum delle varianti greche e slave. In questo ambito hanno cercato di dare il proprio contributo lo scrivente insieme a A. Alberti che in questi anni si sono proposti di analizzare la versione slava considerando i principali "nodi di varianti" della tradizione greca individuati nelle citate pubblicazioni curate dall'INTF.

All'inizio è stato necessario verificare l'applicabilità del metodo e la sua utilità prendendo in considerazione le edizioni esistenti del testo slavo (Voskresenskij, Vajs, Alekseev) e analizzando i nodi di varianti del testo greco contenuti nei primi dieci capitoli del Vangelo di Giovanni, avuti a disposizione in anteprima ${ }^{37}$. Nell'ultimo contributo citato (2009) Garzaniti si è avvalso della collaborazione di A. Alberti per l'analisi di alcuni nodi di varianti greche del vangelo di Marco. La collaborazione si è consolidata con l'analisi dei nodi di varianti dei primi dieci capitoli di Giovanni e dellintero Marco nel Vangelo di Ioan Aleksandr ${ }^{38}$ realizzata per l'edizione di questo codice, che uscirà a cura dell'Accademia delle Scienze bulgara. In seguito Alberti ha proseguito autonomamente analizzando il Vangelo di Elisavetgrad (GBL Muz. 9500) sulla base di ben 467 nodi testuali del testo greco,

\footnotetext{
${ }^{35}$ D. Mironova, Cluster Analysis and the Three Level Method in the Study of the Gospels in Slavonic, [in:] Studies in Stemmatology II, ed. P. Van Reenen, A. Den Hollander, M. Van Mulken, Amsterdam-Philadelphia 2004, p. 241-267.

${ }^{36}$ K. Wachtel, D.C. Parker, The joint IGNTP/INTF Editio Critica Maior...

${ }^{37}$ М. ГАрдзАнити, Перевод и екзегеза на примере Евангелия ияаря Ивана Александра, [in:] Преводите през XIV столетие на Балканите, еd. Л. ТАсевА, М. ЙовчевА, К. ФОС, Т. ПентковСКАя, София 2004, р. 59-69; ІDЕм, Текстология рукописной традиции славянского Евангелия, Sla 78.3-4, 2009, p. 303-312.

${ }^{38}$ М. ГАрдЗАНИТИ, А. АльЕРТИ, Славянская версия греческого текста евангелия: Евангелие Ивана Александра и правка перевода Священного писания, [in:] Проблеми на Кирило-Методиевото дело и на Българска култура през XIV век, София 2007, p. 180-190 (= КМс 17).
} 
all'interno di un corpus slavo di 43 testimoni ${ }^{39}$. Con lo stesso metodo sono stati messi a confronto il Vangelo di Banica, il Vangelo di Dobrejšo (NBKM 17; NBB 214) e quello di Curzon ${ }^{40}$.

Quest'ultimo studio ha potuto avvalersi della pubblicazione in due volumi dedicata interamente al Vangelo di Curzon, curata da Vakareliyska, che offre un'edizione di questo codice ampiamente commentata, uno dei più significativi contributi usciti negli ultimi anni sui vangeli slavi. Nel primo volume si offre la trascrizione del testo con una serie di note paleografiche, che segnalano fra l'altro le mende dei copisti, e un accurato apparato critico in cui si presentano le varianti di una dozzina di codici paleoslavi e paleobulgari. Per la lista del menologio si confronta il Vangelo di Curzon con un numero molto più ampio di fonti. Alla fine si trova un prezioso Index verborum con i corrispondenti termini greci sulla base delledizione di Nestle-Aland (1985, 26 ed.). Nel secondo volume questo tetraevangelo liturgico è descritto accuratamente e messo in relazione in particolare alle testimonianze dei Vangeli di Banica e Dobrejšo ${ }^{41}$.

Più tradizionale è l'edizione del cosiddetto Tetraevangelo macedone (JAZU IIIb7), un codice mutilo e lacunoso della fine del XIV sec., di cui si conservano 146 fogli. Conosciuto anche come Vangelo di Mihanović, giacchè apparteneva alla sua collezione, è stato studiato in passato da diversi studiosi. V. Kostovska insieme alla riproduzione fotografica offre una dettagliata analisi paleografica, ortografico-fonetica, morfologico-sintattica e lessicale del codice. Oltre a certe particolarità lessicali si analizzano i titoli dei "grandi capitoli" zionale analisi linguistica si segnala l'edizione del Vangelo di Evsevij (GBL M.3168; 1282/1283), curata da V. Nimčuk ${ }^{43}$.

Rimanendo nell'area galiziano-voliniana, fra le edizioni fototipiche si ricorda la riproduzione del Vangelo di Luck (GBL Rum.112), un lezionario feriale della seconda metà del XIV sec., promossa dal metropolita di Luc'k e della Volinia, Nifont ${ }^{44}$. Diverse sono oramai le edizioni di codici manoscritti dei vangeli disponibili in rete, sia in trascrizione, come nel progetto promosso dalla Norwegian University of Science and technology (Trondheim) e dalla New Bulgarian University (Sofia) ${ }^{45}$,

\footnotetext{
${ }^{39}$ A. Alberti, Gli scriptoria moldavi e la tradizione mediobulgara. Il caso del Vangelo di Elisavetgrad, [in:] Linee di confine. Separazioni e processi di integrazione nello spazio culturale slavo, ed. G. MorACCI, A. Alberti, Firenze 2013, p. 15-61.

${ }^{40}$ A. Alberti, The Banica, Dobrejšo and Curzon Gospels in Light of the Greek Text, [in:] The Bible in Slavic Tradition, ed. A. Kulik, C.M. MacRobert, S. Nikolova, M. Taube, C.M. Vakareliyska, Leiden-Boston 2016, p. 271-310.

${ }^{41}$ C. Vakareliyska, The Curzon Gospel, vol. I, An Annotated Edition, New York 2008; Eadem, The Curzon Gospel, vol. II, A Linguistic and Textual Introduction, New York 2008.

${ }^{42}$ В. КостовскА, Македонско четвороевангелие, Скопје 2003.

${ }^{43}$ Євсевієве Євангеліє 1283 року, еd. В.В. Нимчук, Киев 2001.

${ }^{44}$ Луцьке евангелие, Луцьк 2011.

${ }^{45}$ Cf. www.hf.ntnu.no/SofiaTrondheimCorpus/notis.html [15 VI 2016].
} 
sia in riproduzione fotografica, come i codici del Fondo slavo della Biblioteca Apostolica Vaticana ${ }^{46}$. Fra le più rilevanti segnaliamo la riproduzione fotografica del Codex Zographensis conservato nella Biblioteca nazionale russa (San Pietroburgo $)^{47}$.

In collaborazione con l'Istituto di Paleoslavistica di Zagabria S.O. Vialova ha curato la pubblicazione dei frammenti glagolitici conservati nella medesima biblioteca a San Pietroburgo. Insieme al volume delle riproduzioni in facsimile si può consultare una dettagliata descrizione dei medesimi con una serie di indici, fra cui si segnala l'indice dei passi biblici che comprende una serie di passi dei vangeli presenti nei messali o nei breviari ${ }^{48}$. Ne ha recentemente sottolineato l'importanza Alekseev che ha sviluppato un confronto con l'edizione del Vangelo di Giovanni, da lui diretta ${ }^{49}$.

\section{Saggi sui manoscritti e sulle questioni più rilevanti}

Alla fine di ottobre del 2007, in occasione dei 950 anni dalla realizzazione del Vangelo di Ostromir, si è svolta presso la Biblioteca nazionale russa a San Pietroburgo un'importante conferenza dedicata alla prima testimonianza manoscritta slava orientale e più in generale alla tradizione manoscritta dei codici neotestamentari. Nella prima parte del volume che contiene gli atti, si segnala la riflessione di E.V. Krušel'nickaja sulla sua conservazione e il suo studio, la ricerca di Alekseev sul ruolo di questo lezionario nella tradizione manoscritta delle sacre scritture slave e l'intervento di Popova sulle miniature e la loro ornamentazione. Nella terza sezione dedicata ai manoscritti corredati di notazione musicale si può leggere uno studio di N.V. Ramazanova sulla notazione ecfonetica del famoso lezionario. Molti altri sono i temi trattati nelle diverse sezioni, dalla tradizione manoscritta neotestamentaria conservata in Siberia (V.A. Esipova), ai singoli copisti (Turilov e S.G. Žemajtis), dalle note marginali dei Vangeli nella Bibbia di Gennadij (V.A. Romodanovskaja), ai simboli degli evangelisti (O.V. Čumičeva). Le celebrazioni del giubileo di questo codice sono state accompagnate da una mostra di codici dei vangeli conservati nella medesima Biblioteca, non solo slavi, che vengono presentati con succinte, ma interessanti annotazioni alla fine del volume. Riguardo ai codici slavi meridionali si veda lo studio di Ž.L. Levšina, mentre per i codici slavo orientali si può leggere il contributo O.S. Sapožnikova con E.E. Ševčenko ${ }^{50}$.

\footnotetext{
${ }^{46}$ Cf. www.mss.vatlib.it/gui/scan/link1.jsp?fond=Vat.slav [15 VI 2016].

${ }^{47}$ Cf. http://expositions.nlr.ru/ex_manus/Zograph_Gospel/index.php [15 VI 2016].

${ }^{48}$ S.O. Vialova, Glagoljski fragmenti Ivana Berčića u Ruskoj nacionalnoj biblioteci. Faksimili, Zagreb 2000; EADEM, Glagoljski fragmenti Ivana Berčića u Ruskoj nacionalnoj biblioteci. Opis fragmenata, Zagreb 2000. ${ }^{49}$ А.А. Алексеев, О взаимосвязи правоставной и католической традиции Нового завета в рукописную епоху, Slo 56-57, 2006-2007, p. 57-65.

${ }^{50}$ Остромирово Евангелие и современные исследования рукописной традиции новозаветных текстов. Сборник научных статей, еd. Ж.Л. ЛевшинА, Санкт-Петербург 2010.
} 
Negli anni duemila T.V. Pentkovskaja ha condotto uno studio sistematico sulla lingua del Nuovo Testamento del monastero Čudovskij con una serie di saggi che sono confluiti in un'importante monografia. Tenendo conto del più ampio panorama della revisione dei libri liturgici l'analisi prende in considerazione l'intera famiglia di codici, di cui il manoscritto citato è il principale testimone. La studiosa ha messo in luce come questa redazione testimoni una fase più antica della revisione del Nuovo testamento rispetto alla redazione atonita che si sarebbe diffusa in seguito con finalità diverse $\mathrm{e}^{51}$. Fra le monografie si può segnalare ancora l'interessante monografia di O. Strachova dedicata alla parte glagolitica del Vangelo di Reims (Reims, Bibliothèque municipale), un importante contributo per la ricostruzione delle origini del famoso vangelo, su cui in passato si è molto discusso ${ }^{52}$.

Negli ultimi vent'anni E.M. Vereščagin ha pubblicato una serie di contributi che hanno trovato la loro sistemazione in un'ampia monografia incentrata proprio sulla testimonianza del Vangelo di Ostromir e che rappresenta la più matura espressione delle sue ricerche caratterizzate da un rigido approccio di linguistica sincronica ${ }^{53}$.

Nell'ambito delle ricerche, soprattutto in campo lessicale, si deve menzionare il progetto, coordinato da G. Jovanović in collaborazione con V. Savić, di un "Dizionario dei vangeli slavo-ecclesiastici di redazione serba" che si baserà su una quarantina di testimonianze manoscritte ${ }^{54}$. Se consideriamo la tradizione manoscritta dei vangeli nel più ampio complesso dei "libri sacri", potremmo alla fine menzionare l'edizione del Vangelo didattico di Costantino di Preslav, di cui si deve ancora studiare l'influenza sulla tradizione manoscritta dei vangeli ${ }^{55}$.

Infine si deve accennare ai progressi nella ricostruzione della storia degli studi, di cui abbiamo fatto già menzione a proposito dell'intervento di Krušel'nickaja sul Vangelo di Ostromir (v. supra). In questo ambito merita una particolare menzione la monografia di F. Thomson sul contributo del padre della slavistica, J. Dobrovskýs ${ }^{56}$.

\footnotetext{
${ }^{51}$ Т.В. ПЕнтковскАя, К истории исправления богослужебных книг в Древней Руси в XIV веке: Чудовская редакция Нового Завета, Москва 2009.

${ }^{52}$ In appendice al volume viene presentata una nuova edizione del testo in parallelo con le testimonianze dei messali di Hervoje e di New York. О.Б. Страхова, Глаголическая часть Реймского евангелия. История, язык, текст, Cambridge 2014 (= Psl 22.3).

${ }^{53}$ Е.М. ВерещАгин, Кирилло-Мефодиевское книжное наследие. Межъязыковые, межкультурные и междисииплинарные разыскания. С двумя приложениями, Москва 2012.

${ }^{54}$ Г. Јовановић, В. САвић, Старословенски јеванђетски речник српске редакције, Sla 76, 2007, p. 57-64; Српскословенски речник јеванђель, Огледна свеска, еd. В. САвит, Г. Јовановит, Београд 2007 (= БЈф 23).

${ }_{55}^{5}$ Старобългарското Учително Евангелие на Константин Преславски, еd. М. Тихова, Е. УхАнова, Freiburg im Breisgau 2012.

${ }^{56}$ F. Thomson, Dobrowsky and the Slavonic Bible: Josef Dobrowsky's Contribution to the Study of the Slavonic Bible together with a Survey of Previous Scholarship and an Appreciation of his Lasting Influence on Slavic Biblical Studies, Praha 2004.
} 


\section{Conclusioni}

Questa breve presentazione delle pubblicazioni dedicate alla tradizione manoscritta dei vangeli nello scorcio di questo nuovo millennio ci mostra i notevoli progressi chi sono stati fatti, ma allo stesso tempo il permanere di alcuni limiti nelle ricerche in quest'ambito.

Certamente la slavistica rimane all'avanguardia nell'ambito dello studio della struttura del libro dei vangeli slavi nei confronti degli studi neotestamentari greci. Le ricerche odierne ci consentono di comprendere meglio la funzione sia del lezionario sia del tetraevangelo nella loro evoluzione storica all'interno del complesso dei libri liturgici. In questo modo il libro dei vangeli ritrova il suo più autentico contesto a servizio delle comunità soprattutto della Slavia ortodossa, senza escludere comunque la tradizione glagolitica d'area croata nell'ambito della Slavia latina. Questa ricostruzione può avere delle ricadute positive anche nello studio della tradizione testuale in cui, invece, si osservano ancora limiti notevoli rispetto agli studi neotestamentari greci.

Certamente rappresenta un fatto positivo che per la prima volta si sia adottato un metodo statistico per la ricostruzione della tradizione manoscritta slava e per la realizzazione di una nuova edizione scientifica. Trattandosi di un primo tentativo è naturale che si possano riscontrare dei limiti, ma si è intrapresa la direzione giusta che si sta già percorrendo anche per l'originale greco pur in forme diverse. In quest'ultimo ambito l'attenzione rimane rivolta alla costruzione del testo più antico, mentre nell'ambito slavo ci si concentra maggiormente sulla sua evoluzione nelle diverse epoche e aree geografiche.

Questo precipuo interesse per le relazioni con il territorio, tuttavia, può ridurre lo studio della tradizione manoscritta slava dei vangeli a puro materiale linguistico per la ricostruzione della storia delle diverse redazioni dello slavo ecclesiastico oppure per evidenziare l'influenza delle singole parlate slave. Lo testimoniano talvolta gli studi paleografici e linguistici soprattutto in ambito lessicale su cui ci siamo solo brevemente soffermati.

Ne emerge un panorama che evidenzia tutta la complessità della ricerca sulla tradizione manoscritta dei vangeli il cui studio implica ampie conoscenze nell'ambito delle diverse discipline, dalla paleografia alla storia dell'arte, dalla linguistica alla critica testuale mettendo inevitabilmente a dura prova lo studioso. Questo, inevitabilmente, dovrà portare sempre di più alla creazione di gruppi di lavoro formati da specialisti con competenze diverse. Si tratta, dunque, di un campo in estrema evoluzione e in grado di offrire nuove interessanti prospettive negli studi filologici slavi che speriamo possano essere percorse nei prossimi anni. 


\section{Bibliografia}

Aland B., K. Aland, The Text of the New Testament. An Introduction to the Critical Editions and the Theory and Practice of Modern Textual Criticism, Grand Rapids-Leiden 1987.

Alberti A., Gli scriptoria moldavi e la tradizione mediobulgara. Il caso del Vangelo di Elisavetgrad, [in:] Linee di confine. Separazioni e processi di integrazione nello spazio culturale slavo, ed. G. Moracci, A. Alberti, Firenze 2013, p. 15-61.

Alberti A., The Banica, Dobrejšo and Curzon Gospels in Light of the Greek Text, [in:] The Bible in Slavic Tradition, ed. A. Kulik, C.M. MacRobert, S. Nikolova, M. Taube, C.M. VakareliYSKA, Leiden-Boston, p. 271-310.

Birkfellner G., Codex Hankenstein. Codex Vindobonensis slavicus 37. Altukrainisches liturgisches Anthologion des 13.-14. Jahrhunderts. Textus manuscriptus linguae ecclesiastico-slavonicae versionis ucrainicae (parvorossicae) saeculi XIII-XIV, vol. II, Neutestamentliche Perikopen, Evangelien und Apostelschriften, Münster 2006.

Garzaniti M., Die altslavische Version der Evangelien. Forschungsgeschichte und zeitgenössische Forschung, Köln-Weimar-Wien 2001.

Garzaniti M., Il culto dei santi nella Slavia ortodossa alla luce dei libri del Vangelo e dell'Apostolo. Prima parte, [in:] Liturgia e agiografia tra Roma e Costantinopoli, ed. K. StAnTCHEv, S. PARENTI, Grottaferrata 2007, p. 89-108.

Garzaniti M., Il culto dei santi nella Slavia ortodossa: la testimonianza dei libri del Vangelo e dell' Apostolo. Sviluppi storici e diffusione geografica: l'eredità bizantina e la formazione della prima tradizione manoscritta (X-XI sec.), [in:] Il tempo dei santi tra Oriente e Occidente. Liturgia e agiografia dal tardo antico al Concilio di Trento, ed. A. Benvenuti, M. Garzaniti, Roma 2005, p. 311-341.

Garzaniti M., The Gospel Book and its Liturgical Function in the Byzantine-Slavic Tradition, [in:] Catalogue of Byzantine Manuscripts in their Liturgical Context, vol. I, Challenges and Perspectives, ed. K. Spronk, G. Rouwhorst, S. Royé, Turnhout 2013, p. 35-54.

JAGIĆ V., Ein Beitrag zur Erforschung der altkirchenslavischen Evangelientexte (Evangelium Bucovinense), Wien 1916.

Jordan Ch.R.D., The Textual Tradition of the Gospel of John in Greek Gospel Lectionaries from the Middle Byzantine Period ( $8^{\text {th }}-11^{\text {th }}$ Century). A Thesis Submitted to The University of Birmingham for the Degree of Doctor of Philosophy, Birmingham 2009, www.etheses.bham.ac.uk/578/1/ Jordan10PhD.pdf [29 VI 2016].

Mink G., Problems of a highly Contaminated Tradition: the New Testament. Stemmata of Variants as a Source of a Genealogy for Witnesses, [in:] Studies in Stemmatology II, ed. P. VAn ReEnen, A. Den Hollander, M. Van Mulken, Amsterdam-Philadelphia 2004, p. 13-86.

Mironova D., Cluster Analysis and the Three Level Method in the Study of the Gospels in Slavonic, [in:] Studies in Stemmatology II, ed. P. Van Reenen, A. Den Hollander, M. Van Mulken, Amsterdam-Philadelphia 2004, p. 241-267.

Moussakova E., The Illuminated Old-Bulgarian Gospel Lectionaries in the Light of their probable Byzantine Models, [in:] Древнерусское искусство. Искусство рукописной книги. Византия. Древняя Русь, ed. Е.Н. Добрынина, Санкт-Петербург 2004, p. 277-289.

OstapCzuk J., Cerkiewnosłowiański przekład liturgicznych perykop okresu paschalnego i święta Pięćdziesiątnicy w rękopiśmiennych ewangeliarzach krótkich, Warszawa 2010. 
Ostapczuk J., Sobotnie i niedzielne perykopy liturgiczne z Ewangelii Mateusza w cerkiewnosłowiańskich lekcjonarzach krótkich, Warszawa 2013.

Text und Textwert der Griechischen Handschriften des Neuen Testaments. IV. Die Synoptischen Evangelien. 1. Das Markusevangelium, ed. K. Aland, B. Aland, K. Wachtel, K. Witte, vol. II, Berlin-New York 1998.

Text und Textwert der Griechischen Handschriften des Neuen Testaments. IV. Die Synoptischen Evangelien, 2. Das Matthäusevangelium, ed. K. Aland, B. Aland, K. Wachtel, K. Witte, vol. II, Berlin-New York 1999.

Text und Textwert der Griechischen Handschriften des Neuen Testaments. IV. Die Synoptischen Evangelien. 3. Das Lukasevangelium, ed. K. Aland, B. Aland, K. Wachtel, K. Witte, vol. II, Berlin-New York 1999.

Text und Textwert der Griechischen Handschriften des Neuen Testaments. V. Das Johannesevangelium, ed. K. Aland, B. Aland, K. Wachtel, K. Witte, vol. II, Berlin-New York 2005.

The Gospel According to John in the Byzantine Tradition, ed. R.L. Mullen, S. Crisp, D.C. PArker, Stuttgart 2007.

The Gospel According to St John. The Majuscules, ed. U.B. Schmid, W.J. Elliott, D.C. Parker, Leiden 2007 (= NTTSD 37).

The Gospel According to St John. The Papyri, ed. W.J. Elliott, D.C. PArker, Leiden 1995 (= NTTS 20).

The Gospel According to St Luke. Part One. Chapters 1-12, ed. The American and British Committees of the International Greek New Testament Project, Oxford 1984.

The Gospel According to St Luke. Part Two. Chapters 13-24, ed. The American and British Committees of the International Greek New Testament Project, Oxford 1987.

Thomson F., Dobrowsky and the Slavonic Bible: Josef Dobrowsky's Contribution to the Study of the Slavonic Bible together with a Survey of Previous Scholarship and an Appreciation of his Lasting Influence on Slavic Biblical Studies, Praha 2004.

Vakareliyska C., A Typology of Slavic Menology Traditions, [in:] American Contributions to the $X I V^{\text {th }}$ International Congress of Slavists (Ohrid 2008), vol. I, Linguistics, ed. СH.Y. BETHIN, Bloomington 2008, p. 227-244.

Vakareliyska C., D. Birnbaum, A Computerized Database of Medieval Slavic Gospel Menologies, [in:] Слово: Към израждане на дигитална библиотека на южноставянски рбкописи. Доклади от международната конференция 21-26 февруари, 2008, София, България, еd. Х. Миклас, А. МилтеновА, София 2008, р. 220-226.

VakareliYska C., The Curzon Gospel, vol. I. An Annotated Edition, New York 2008.

Vakareliyska C., The Curzon Gospel, vol. II. A Linguistic and Textual Introduction, New York 2008.

VIALova S.O., Glagoljski fragmenti Ivana Berčića u Ruskoj nacionalnoj biblioteci. Faksimili, Zagreb 2000.

VIALova S.O., Glagoljski fragmenti Ivana Berčića u Ruskoj nacionalnoj biblioteci. Opis fragmenata, Zagreb 2000.

Wachtel K., Parker D.C., The Joint IGNTP/INTF Editio Critica Maior of the Gospel of John. It's Goal and their Significance for New Testament Scholarship Proposed Paper for SNTS 2005 (Halle), www.uni-muenster.de/INTF/ECM\%20Halle6.pdf [15 VI 2016].

Wachtel K., Der Byzantinische Text der Katholischen Briefe. Eine Untersuchung zur Entstehung der Koine des Neuen Testaments, Berlin 1995. 
Алексевв А.А., О взаимосвязи православной и католической традиции Нового завета в рукописную эпоху, Slo 56-57, 2006-2007, p. 57-65.

ВЕРещАгин Е.М., Кирилло-Мефодиевское книжное наследие. Межъязыковые, межкультурные и междисииплинарные разыскания. С двумя приложениями, Москва 2012.

ГАРДЗАнити М., А. АльЕРти, Славянская версия греческого текста евангелия: Евангелие Ивана Александра и правка перевода Священного писания, [in:] Проблеми на Кирило-Методиевото дело и на Българска култура през XIV век, София 2007, p. 180-190 (= КМс 17).

ГАрдзАнити М., Перевод и екзегеза на примере Евангелия царя Ивана Александра, [in:] Преводите през XIV столетие на Балканите, еd. Л. ТАсевА, М. ЙовчевА, К. ФоС, Т. ПентковСКАя, София 2004, р. 59-69.

ГАрдзАнити М., Текстология рукописной традиции славянского Евангелия, Sla 78.3-4, 2009, p. 303-312.

ДограмаджиЕва Е., Месеиесловните четива в славянските ръкописни евангелия (X-XVII в.), София 2010 (= КМс 19).

Євсевієве Євангеліє 1283 року, ед. В.В. Нимчук, Киев 2001.

Јовановић Г., В. САвић, Старостовенски јеванђетьски речник српске редакиије, Sla 76, 2007, p. 57-64.

Костовска В., Македонско четвороевангелие, Скопје 2003.

Лосева О.В., Русские месяцесловы XI-XIV веков, Москва 2001.

Луцьке евангелие, Луцьк 2011.

Мусакова Е., Графическата сегментация на текста в Асеманиевото евангелие, Slo 56-57, 2006-2007, p. 391-404.

Остромирово Евангелие и современные исследования рукописной традиции новозаветных текстов. Сборник научных статей, еd. Ж.Л. Левшина, Санкт-Петербург 2010.

Пентковская Т.В., К истории исправления богослужебных книг в Древней Руси в XIV веке: Чудовская редакиия Нового Завета, Москва 2009.

Сводный каталог славяно-русских рукописных книг, хранящихся в России, странах СНГ и Балтии. ХIV век, vol. I (Апокалипсис - Летопис Лаврентьевская), еd. О.А. КнязевскАЯ, Н.А. КоБяк, А.Л. ЛиФшиц, Н.Б. Тихомиров, А.А. Турилов, Н.Б. ШелАмАновА, Москва 2002.

Смирнова Е.С., Миниатюры Остромирова Евангелия. Особенности иконограбии, [in:] Образ Византии. Сборник статей в честь О.С. Поповой, еd. А.В. ЗАХАрова, Москва 2008, p. $457-472$.

Српскословенски речник јеванђела, Огледна свеска, еd. В. САвић, Г. ЈовАновит, Београд 2007 (= БЈф 23).

Старобългарското Учително Евангелие на Константин Преславски, еd. М. Тихова, Е. УхАновА, Freiburg im Breisgau 2012.

Страхова О.Б., Глаголическая часть Реймского евангелия. История, язык, текст, Cambridge 2014 (= Psl 22.3).

ТАлев И.В., Бблгарски “предренесанс". Митове и реалност, София 2005.

Темчин С.Ю., О возможном балканском влиянии на структуру церковнославянских богослужебных книг ВКЛ и Польского Королевста, SRu 18, 2000, p. 275-280. 
Темчин С.Ю., Столпный апракос - еще один неизвестный структурный тип славянского служебного Евангелия (по рукописям XIII-XVI вв), [in:] Библия в духовной жизни, истории и культуре России и православного славянского мира. К 500-летию Геннадевской Библии. Сборник материалов международной конферениии. Москва, 21-26 сентября 1999 г., еd. Г. БАРАНКОВА, Москва 2001, р. 127-159.

УХанова Е.В., К вопросу о происхождении принцииов обормления глаголичеслих рукописей X-XI вв, [in:] Древнерусское искусство. Искусство рукописной книги. Византия. Древняя $P y c b$, ed. Е.Н. ДоврынинА, Санкт-Петербург 2004, р. 221-244.

УХанова Е.В., Западноевропейские источники в древнерусской книжной културе ХІ века и Остромирово Евангелие, [in:] Путем орнамента. Исследования по искусству Византийского мира. Сборник статей, еd. А.Л. САминский, Москва 2013, p. 206-230.

\begin{abstract}
Recent Researches in the Field of Slavic Gospel. Some Critical Reflections (1999-2016). In the last fifteen years, research on the Slavic Gospel manuscript tradition have reached new and important achievements especially with the spread of computer technology and digitization process. Taking into account progress in the study of the Greek manuscript tradition, the author explains some basic guidelines: the textual structure of the Gospel book, the Menologion pericopes, the Gospel book ornamentation, the new editions. At the end the main essays on individual manuscripts or on particular issues are introduced. The Slavic Gospel, therefore, is still a key issue of Slavic studies in the field of Slavic paleography, textual criticism, and linguistic analysis.
\end{abstract}

Parole chiave: Vangelo slavo, tradizione manoscritta slava, storia della slavistica.

Keywords: Slavic Gospel, Slavic Manuscript Tradition, History of Slavic Studies.

\title{
Marcello Garzaniti
}

Università degli studi di Firenze Dipartimento di Lingue, Letterature e Studi Interculturali

Via S. Reparata, 93-95

50129 Firenze, Italia marcello.garzaniti@unifi.it 